\title{
REVIEW
}

\section{Maintaining the male germline: regulation of spermatogonial stem cells}

\author{
Kyle Caires, Johnathan Broady and Derek McLean \\ Department of Animal Sciences, Center for Reproductive Biology, Washington State University, PO Box 646353, Pullman, Washington 99164-6353, USA \\ (Correspondence should be addressed to D McLean; Email: dmclean@wsu.edu)
}

\begin{abstract}
Spermatogonial stem cells (SSCs) are a self-renewing population of adult stem cells capable of producing progeny cells for sperm production throughout the life of the male. Regulation of the SSC population includes establishment and maintenance of a niche microenvironment in the seminiferous tubules of the testis. Signaling from somatic cells within the niche determines the fate of SSCs by either supporting self-renewal or initiating differentiation leading to meiotic entry and production of spermatozoa. Despite the importance of these processes, little is known about the biochemical and cellular mechanisms that govern SSC fate and identity. This review discusses research findings regarding systemic,
\end{abstract}

endocrine, and local cues that stimulate somatic niche cells to produce factors that contribute to the homeostasis of SSCs in mammals. In addition to their importance for male fertility, SSCs represent a model for the investigation of adult stem cells because they can be maintained in culture, and the presence, proliferation, or loss of SSCs in a cell population can be determined with the use of a transplantation assay. Defining the mechanisms that regulate the self-renewal and differentiation of SSCs will fundamentally improve the understanding of male fertility and provide information about the regulation of adult stem cells in other tissues.

Journal of Endocrinology (2010) 205, 133-145

\section{Introduction}

In animals, tissues require a continual supply of differentiated cells for function. The mammalian testis has a high rate of cell turnover and differentiation as spermatogonia differentiate into spermatozoa throughout the life of the male. The kinetics of sperm production were first described in rodents (Oakberg 1956) with the knowledge of the presence of adult stem cells, such as hematopoietic stem cells (HSCs), scientists hypothesized that germ cell differentiation in the testis required a stem cell population. The presence of a stem cell population responsible for continual sperm production in the testis was demonstrated in 1994 when Brinster \& Zimmermann (1994) documented the first successful spermatogonial stem cell (SSC) transplantation in mice resulting in donor-derived spermatogenesis. Transplantation of a mixed population of germ cells that contain SSCs into the testis of a sterile mouse will restore fertility, although the genetics of the offspring will be of the donor (Avarbock et al. 1996).

Donor-derived spermatogenesis following transplantation is the true test to determine whether a bona fide SSC is present in a cell population. As with other stem cell populations, the ability of an SSC to colonize and initiate the formation of progeny cells depends on the microenvironment surrounding the SSC. The microenvironment, or niche, in the seminiferous tubule where SSCs are present appears to be critical for the production of progeny spermatogonia based on the difficulty of recapitulating this process in vitro or across species. However, the potential of SSCs does not appear to be limited to germ cells. Several research groups have reported that cells can be isolated from the testis and induced in culture to form embryonic-like stem cells with the ability to differentiate into multiple differentiated cell lineages (Kanatsu-Shinohara et al. 2004, Guan et al. 2006, Seandel et al. 2007). Indeed, transdifferentiation of stem/progenitor spermatogonia can produce tissues of all three germ layers, including prostatic, uterine, and skin epithelium as demonstrated in mice (Simon et al. 2009). These recent advances in the field underscore the potential use of SSCs for biomedical applications in regenerative medicine and provide a model to improve our basic understanding of adult stem cell populations.

Restoration of fertility following SSC transplantation in rodents suggests therapeutic potential for the technique in humans. Therapeutic uses of other adult stem cells such as HSCs motivate research to determine the basic mechanisms regulating the stem cells and the cells and factors that contribute to the stem cell niche (Yan \& Owens 2008, Zon 2008). Similarly, identification of the downstream cellular signaling in SSCs following treatment with regulatory factors 
such as glial cell line-derived neurotropic factor (GDNF) is being intensely studied because it will impact the ability to maintain human SSCs in vitro for therapeutic purposes (Orwig \& Schlatt 2005, Kubota \& Brinster 2006). Likewise, investigation of factors regulating SSCs in species besides mice suggests that comparative similarities will accelerate the application of SSC in both human health and agricultural species (Oatley et al. 2004, Ryu et al. 2005, Kanatsu-Shinohara et al. 2008).

This review will focus on SSC biology primarily depending on information gained from rodent models. We will emphasize several topics in the field where research findings have stimulated new hypotheses about the formation and maintenance of the SSC population. The importance of SSC function will be linked to the general understanding of spermatogenesis and the endocrine regulation of this process. For example, the formation of the SSC population and associated niche in the testis is critical to the initiation of spermatogenesis and the long-term production of sperm. Likewise, maintenance of the SSC population is likely regulated by different processes than the formation of the SSC population but equally important for the production of sperm throughout the life of the male. Also of particular emphasis in this review is the GDNF-regulated signaling involved in SSC proliferation and self-renewal because of its importance for SSC maintenance.

\section{Spermatogonia}

The continual production of sperm by sexually mature males requires an efficient and highly regulated process in the seminiferous tubules of the testis (Sharpe 1994). The somatic Sertoli cells of the seminiferous epithelium support the differentiation of germ cells from diploid undifferentiated spermatogonia to mature, haploid spermatozoa that are morphologically distinct from all other cells in the testis. In most species, this is a remarkably productive process highlighted by species which produce over a billion sperm each day (Sharpe 1994). Thus, a constant supply of undifferentiated spermatogonia must be maintained so that these cells can differentiate into sperm (de Rooij \& Russell 2000). The cell responsible for supplying undifferentiated spermatogonia is the SSC. After the prepubertal initiation of germ cell differentiation, spermatogenesis is maintained by the ability of SSCs to provide a continual supply of differentiating spermatogonia. This is a hallmark of a population of stem cells taken from an adult organ - the ability to endlessly self-renew to create additional stem cells and cells destined for differentiation (Fuchs et al. 2004). To maintain this ability, adult stem cells need to reside in a niche environment that supplies factors and provides interactions crucial for their survival and development. The niche is defined as the microenvironment that maintains the fate of the stem cell by preventing its differentiation and is usually composed of adjacent differentiated cells, the stem cells themselves, and the extracellular matrix surrounding these cells. Niche environments vary depending on which organ or tissue the stem cell resides, and these niches are not always clearly defined (Spradling et al. 2001). Extrinsic regulation of the SSC self-renewal/differentiation process is thought to occur by the production of factors by somatic cells that contribute to the SSC niche in the seminiferous tubule (Shinohara et al. 2001, Spradling et al. 2001).

In the seminiferous tubule of the testis, germ cells are present at different phases of differentiation - from round, diploid spermatogonia near the basement membrane to haploid spermatozoa with a fully formed tail near the lumen. The SSC population is part of a subset of male germ cells called undifferentiated spermatogonia (de Rooij \& Russell 2000). This subset includes $A_{\text {single }}\left(A_{s}\right)$ spermatogonia that are thought to be the SSCs and their progeny cells $A_{\text {paired }}$ $\left(A_{p r}\right)$ and $A_{\text {aligned }}\left(A_{\text {al }}\right)$ spermatogonia. The ultimate test for an adult stem cell is the ability to regenerate functional differentiated cells in the tissue of origin. Based on our current knowledge, SSCs (i.e. $\mathrm{A}_{\mathrm{s}}$ spermatogonia) are capable of colonizing the seminiferous tubules in the testes of recipient mice resulting in long-term sperm production. In contrast, the conventional wisdom is $\mathrm{A}_{\mathrm{pr}}$ or $\mathrm{A}_{\mathrm{al}}$ spermatogonia are not capable of colonizing seminiferous tubules or subsequently producing sperm. Under normal conditions in the testis of an adult, the $A_{a l}$ spermatogonia differentiate without undergoing mitosis into type $A_{1}$ spermatogonia, the first spermatogonial cell type that is considered to be differentiated and associated with a stage of spermatogenesis (de Rooij \& Grootegoed 1998). The differentiation pathway of undifferentiated spermatogonia and differentiated spermatogonia provides the foundation of how thousands of sperm are produced from a single SSC. Morphological characterization of the seminiferous tubules was used to estimate the number of $A_{s}$ cells at $\sim 35000$ in the testis of a mouse (Meistrich \& van Beek 1993) and 330000 total type $A_{s}$, $A_{\mathrm{pr}}, \mathrm{A}_{\mathrm{al}}$ undifferentiated spermatogonia (Tegelenbosch \& de Rooij 1993). Interestingly, although morphologically distinct from one another, there are numerous examples of proteins that are expressed across the undifferentiated spermatogonia lineage but not expressed in more differentiated spermatogonia (types $\mathrm{A}_{1}-\mathrm{A}_{4}$, Intermediate, $\mathrm{B}$ ), spermatocytes, and spermatids (Table 1). These proteins therefore may serve as markers for an undifferentiated state but not a stem cell state.

\section{Spermatogonial stem cells}

As is evident from the descriptive name, $A_{\mathrm{pr}}$ spermatogonia are two undifferentiated spermatogonia derived from a single SSC that maintain a cytoplasmic bridge. The SSC would therefore also have the potential to divide and become two new SSCs. Based on the formation of $A_{p r}$ spermatogonia from an SSC, it appears unlikely that a SSC can divide and form one $A_{p r}$ spermatogonia and a new SSC. Thus, mammalian 
Table 1 Genes associated with spermatogonial stem cells and undifferentiated spermatogonia. No gene product has been identified as spermatogonial stem cell specific; all genes in this list are expressed in the pool of undifferentiated spermatogonia

\section{Primary references}

$\begin{array}{ll}\text { Gene symbol } & \\ \text { Zbtb16 (Plzf) } & \text { Buaas et al. (2004) } \\ \text { Neurog3 (Ngn3) } & \text { Yoshida et al. (2004) } \\ \text { Gfra1 (Gfra1) } & \text { Naughton et al. (2006) } \\ \text { Ret } & \text { Naughton et al. (2006) } \\ \text { Utp14b (jsd) } & \text { Boettger-Tong et al. (2000) and } \\ \text { Shetty et al. (2006b) } \\ \text { Pou5f1 (oct4) } & \text { Pesce et al. (1998) } \\ \text { Bcl6b } & \text { Oatley et al. (2006) } \\ \text { Etv5 (erm) } & \text { Oatley et al. (2007) and } \\ & \text { Schlesser et al. (2008) } \\ \text { Lhx1 } & \text { Oatley et al. (2007) } \\ \text { Nanos2 } & \text { Sada et al. (2009) }\end{array}$

SSCs appear limited to symmetrical division, in which the parent stem cell forms either two new stem cells or two daughter cells committed to differentiation. However, we cannot be completely confident that mammalian SSC division occurs in this manner. For example, the male germline stem cell division in Drosophila melanogaster divides in an asymmetrical manner. In this system, the male germline stem cell is attached to a hub cell, and when signaled, it divides to become another germline stem cell or differentiates into a sperm cell (Tegelenbosch \& de Rooij 1993, Fuller \& Spradling 2007). Detailed illustrations of the potential symmetrical and asymmetrical division and the relationship of SSCs with other germ cells and somatic cells in the testis have been described (Oatley \& Brinster 2008). The process of SSC self-renewal and commitment to differentiation is an important aspect of germ cell differentiation and the basis of two fundamental questions. First, what is the signal that stimulates an SSC to begin the process of differentiation? And second, what is the signal that stimulates an SSC to divide to self-renew the SSC population? In other words, how is an SSC controlled to divide into two $A_{p r}$ spermatogonia or form two new SSCs? Thus, based on this description, once spermatogonia initiate the transition from a SSC to an $\mathrm{A}_{\mathrm{pr}}$ spermatogonia, the daughter $A_{p r}$ spermatogonia no longer have stem cell potential. This hypothesis is generally accepted; however, this is based on little or no experimental evidence.

$\mathrm{A}_{\mathrm{s}}$ spermatogonia are considered the true SSC population, but it is unclear if all $A_{s}$ spermatogonia are SSCs, or if a subpopulation of $A_{s}$ spermatogonia have stem cell activity. To investigate the ability of undifferentiated spermatogonia to contribute to germline stem cell activity in the mouse, Nakagawa et al. (2007) used a transgenic mouse that expressed green fluorescent protein (GFP) under the regulation of the Neurog3 (Ngn3) promoter after treating the mouse with tamoxifen. Ngn3 is expressed by undifferentiated spermatogonia so this transgenic mouse model is useful for investigating the fate of undifferentiated spermatogonia by means of tracking GFP expression (Yoshida et al. 2004). Results of experiments in which the fate of germ cells following the induction of GFP that were injected into testes of recipient mice guides these researchers to conclude that there are two populations of SSCs in the mouse testis (Nakagawa et al. 2007). The first is an actual (or stable) SSC population, which is present throughout the life of the animal, and the ability of these cells to self-renew decreases as the animal ages. The second is a population of SSCs called potential germline stem cells, which is capable of self-renewal, but this activity does not occur under normal conditions. Instead, the second population of cells is characterized by a rapid turnover rate suggesting that they belong to a transitamplifying, (rather than the dormant) population to provide differentiated spermatogonia. In contrast, potential germline stem cells shift their activity from differentiation to that of self-renewal (as stem cells) when the testis is damaged or if the cells are transplanted to another testis. In addition, the potential germline stem cells are responsible for supplying self-renewing stem cells to the testis as the actual SSCs are lost over time during normal aging (Nakagawa et al. 2007). Nakagawa et al. (2007) hypothesized that potential germline stem cells are found in the $A_{p r}$ population. This hypothesis implies that the $A_{p r}$ spermatogonia can break cytoplasmic bridges to gain the ability to self-renew. The enzymatic digestion of the testis used in SSC transplantation experiments breaks the cytoplasmic bridges between $A_{p r}$ spermatogonia and all germ cells, which potentially stimulates $A_{p r}$ spermatogonia to initiate self-renewal. Likewise, damage to the testis by chemical or other insult would provide a signal for $A_{p r}$ spermatogonia to break bridges and initiate selfrenewal. Therefore, as actual SSCs are lost due to aging, $A_{p r}$ spermatogonia self-renewal could be stimulated by a variety of intrinsic or extrinsic cues including SSC death, differentiation or by systemic factors.

In addition to investigating the SSC populations in mice, Nakagawa et al. (2007) also used this system to estimate the number of cells in the actual SSC population. They concluded that the number of actual SSCs is $\sim 2000$ cells, a number much lower than the 35000 estimated for $A_{s}$ spermatogonia based on morphological analysis of the seminiferous tubule (see above). The estimate by Nakagawa et al. (2007) is closer to another independently derived estimate of $\sim 3000$ germ cells capable of colonizing the seminiferous testis of a recipient mouse (Nagano 2003). These data were obtained with the use of SSC transplantation, which based on interpretation of the findings by Nakagawa et al. (2007) may not accurately represent the actual or stable SSC population. Other factors also influence interpretation of SSC transplantation data, including SSC homing efficiency or the ability of a SSC to establish a niche in the testis of the recipient animal. Homing efficiency of SSCs in the seminiferous tubules of a recipient mouse has been estimated to be $10-12 \%$ and may vary depending on the age of the recipient or the technique used to eliminate the differentiating 
germ cells from the testis of the recipient (Nagano 2003). For example, bulsulfan treatment or irradiation can eliminate endogenous spermatogenesis (Creemers et al. 2002, McLean 2008) but irradiation damages Sertoli cells reducing the ability of transplanted SSCs to colonize and initiate differentiation (Zhang et al. 2007). Comparison of SSC colonization between irradiated and bulsulfan-treated recipients requires consideration of somatic cell damage that alters SSC colonization efficiency and subsequent differentiation. Moreover, the true number of SSCs, actual or potential, can only be determined if an SSC-specific marker is identified.

\section{GDNF-regulated SSC self-renewal}

The second fundamental question about SSC self-renewal what is the signal that stimulates an SSC to divide and replenish the SSC population, has been at least partially answered with the use of in vivo mouse models and work investigating SSC self-renewal in vitro. As will be described in more detail below, GDNF is an essential factor for the proliferation and simultaneous self-renewal of SSCs. It is difficult to consider the question of SSC differentiation and SSC self-renewal independently. For example, it is not known if the loss of direct GDNF signaling in vivo to a SSC is the primary determinant leading to the differentiation of SSCs or if other factors are involved. It appears that when SSCs are cultured under serumfree conditions in a defined medium containing GDNF, soluble GFR $\alpha 1$, and basic fibroblast growth factor (bFGF) that the removal of GDNF from the culture leads to changes in the appearance of SSCs such that they no longer maintain cell contacts or clumps of cells (Oatley et al. 2006). This result was verified independently using slightly different culture conditions for SSCs that included GDNF, epidermal growth factor, and bFGF, in which removal of GDNF resulted in a significantly decreased number of SSCs in vitro (Lee et al. 2007). The situation in vivo is likely more complex because it would be difficult to envision a mechanism that would completely remove GDNF from the SSC niche microenvironment. However, GDNF may be sequestered in the niche by the extracellular matrix creating a gradient that results in SSC differentiation into spermatogonia as cells move away from high concentrations of GDNF. Such a mechanism may be necessary because the expression of GDNF and its cognate receptors GFR $\alpha 1$ and RET does not appear to be stage specific or associated within limited regions of the seminiferous tubule (Meng et al. 2000, Fouchecourt et al. 2006, Naughton et al. 2006). Although there are differences in the expression of these proteins between species, the expression patterns of GDNF, GFR $\alpha 1$, and RET in somatic and germ cells of the testis suggest that other factors are involved in signaling SSCs to commit to the spermatogonial differentiation pathway (Fig. 1). Alternatively, it is important to note that the expression patterns of RET detected by a general antiRET antibody and a phosphorylation-specific RET antibody are different. The phosphorylation-specific anti-RET staining

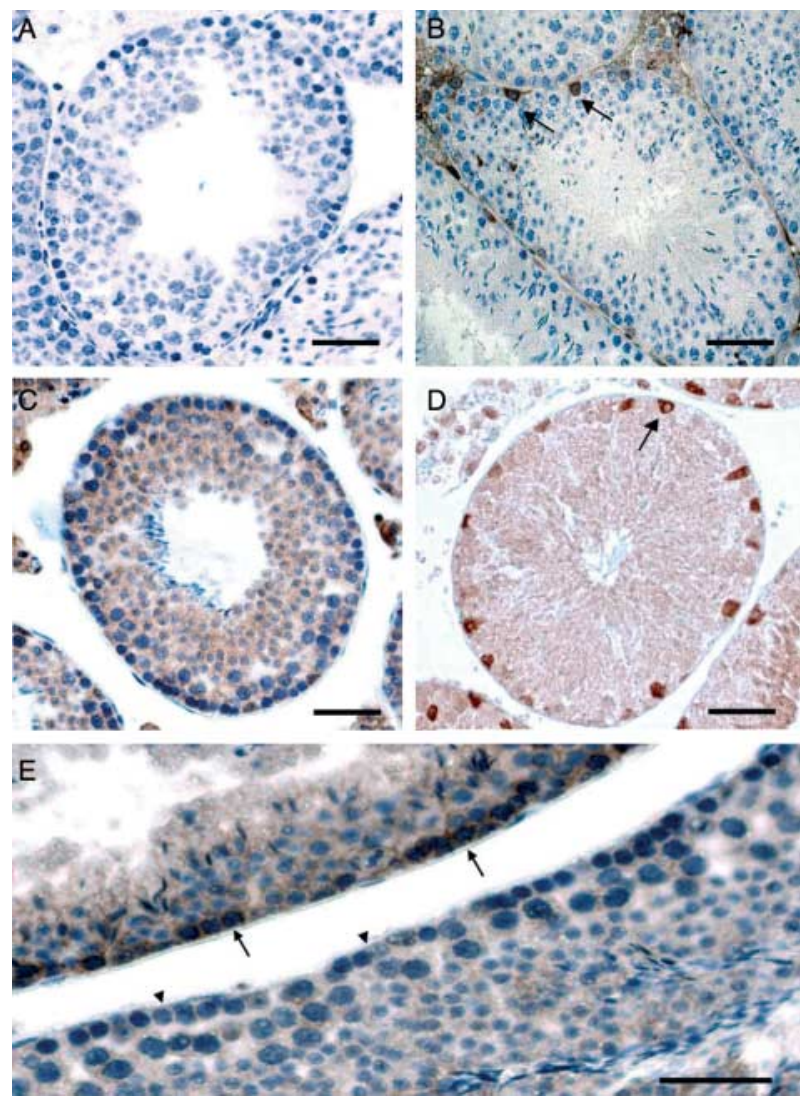

Figure 1 Photomicrographs of cross-sections of seminiferous tubules in an adult mouse testis used for immunohistochemical analysis. (A) Control hematoxylin counter-stained mouse testis section with no primary antibody incubation. (B) Immunohistorchemistry staining for PLZF. Undifferentiated spermatogonia positive for PLZF (arrows) are found along the basement membrane preferentially localized to the interstitial space. The image also demonstrates that not all seminiferous tubules contain PLZFpositive spermatogonia. Cells with positive stain in the interstitial space are non-specific, while staining in seminferous tubules is specific for PLZF based on controls. (C) Immunohistochemistry staining for GDNF. Somatic and germ cells are positive for GDNF in all seminiferous tubules regardless of stage. (D) Immunohistochemistry for RET. Spermatogonia along the basement membrane are positive for RET (arrows) with some expression visualized in Sertoli cells. No counterstain was used to assist in the visualization of RET-positive cells. (E) Immunohistochemistry staining for phosphorylation-specific Tyrosine 1062 (Y-1062) residue of RET in germ and somatic cells. The importance of intracellular signaling via Y-1062 in RET has been demonstrated for spermatogonial stem cell self-renewal in mammals. The image illustrates that expression of RET phosphorylated in Y-1062 is heterogeneous among seminiferous tubules. Spermatogonia positive for RET-Y-1062 staining are indicated with an arrow, and negative spermatogonia in the adjacent tubule are indicated with an arrowhead. Scale bar is $50 \mu \mathrm{m}$ in all panels. Images are representative of independent experiments $(n=3)$.

has stage-specific characteristics in contrast to the staining observed with the use of the general anti-RET antibody (Fig. 1). This raises the possibility that the phosphorylation and subsequent dephosphorylation of RET may be important 
cellular mechanisms to regulate the self-renewal or differentiation of SSCs in a niche- or stage-specific way.

GDNF expression in the testis needs to be tightly regulated for normal germ cell differentiation and sperm production. An accumulation of undifferentiated spermatogonia due to the inability to differentiate occurs in mice genetically modified to overexpress GDNF resulting in infertility (Meng et al. 2000). Interestingly, attempts to induce spermatogonial differentiation with retinoic acid (RA) treatment in the GDNF overexpressing mice resulted in apoptosis of undifferentiated spermatogonial clumps (Meng et al. 2000). RA stimulates undifferentiated spermatogonia to differentiate into type $A_{1}$ spermatogonia, the first differentiating germ cell that is associated with stages of the seminiferous epithelium. Therefore, GDNF and RA signaling represents two independent means for regulating germ cell maturation, and abnormal expression of GDNF suppresses spermatogonial differentiation.

Transplantation of SSCs from transgenic mice overexpressing GDNF described by Meng et al. (2000) into the testes of irradiated mice resulted in successful colonization of the donor cells. However, undifferentiated spermatogonia formed clumps in the seminiferous tubules of recipient testes similar to the phenotype observed in the transgenic donor mice (Creemers et al. 2002). These results suggest that high expression of GDNF in spermatogonia is the basis of the phenotype observed in this transgenic mouse line. Both Sertoli cells and differentiating germ cells express GDNF mRNA and protein in the rat indicating that paracrine and autocrine regulation occurs in these cell types (Fouchecourt et al. 2006). Precise SSC transplantation experiments using cell-sorting approaches to enrich for SSCs could be used to determine if the proportion of SSCs in the GDNF over-expressing mice was higher than in control mice of similar age. This experimental approach would demonstrate if the SSC population in vivo could be manipulated by altering the concentration offactors known to regulate SSC activity within the niche. The GDNF overexpression transgenic mouse model demonstrates that the precise expression of GDNF is important for spermatogonial differentiation and normal germ cell maturation, especially considering that as the transgenic mice age, they develop testicular tumors (Meng et al. 2001).

\section{GDNF signaling in SSCs}

Based on the importance of GDNF for SSC proliferation/ self-renewal and to maintain SSCs in culture, the cell signaling cascade activated by this factor is of intense interest. In spermatogonia, GDNF binds to GFR $\alpha 1$, which is linked to the plasma membrane by a glycosyl-phosphatidylinositol anchor (Airaksinen \& Saarma 2002). The GDNF-GFR $\alpha 1$ complex recruits two molecules of the receptor tyrosine kinase RET to lipid rafts in the plasma membrane, thereby activating autophosphorylation and intracellular signaling. Cellular and physiological actions of RET activation by GDNF binding have been demonstrated in the kidney, neural tissue, and the testis (Sariola \& Saarma 2003). RET is a transmembrane receptor tyrosine kinase that is subject to alternative splicing resulting in two forms of the protein, RET9 and RET51 (Santoro et al. 2004), and both forms of RET are expressed in SSCs (Oatley et al. 2007). RET has a typical intracellular kinase domain with 12 autophosphorylation sites that can activate multiple signaling pathways (Santoro et al. 2004). Mutations of the ret gene can lead to cancer in multiple tissues including thyroid, intestine, and neurons associated with other tissues (Santoro et al. 2004). Specific alterations to the RET protein also alter germ cell differentiation. For example, mice heterozygous for mutations in two amino acid residues within the cytoplasmic tail of RET had fewer spermatogonia at day 10 after birth when compared to controls (Jain et al. 2004). Further verification of the importance of GDNF, GFR $\propto 1$ and RET for spermatogonial proliferation and survival was demonstrated with the use of whole testis transplantation of testes from GDNF-/ - , GFR $\alpha 1-/-$, and RET $-/-$ mice at the day of birth. These experiments demonstrated that during the first week of testis development, there is significant germ cell depletion due to the lack of spermatogonial proliferation. However, it was not confirmed by SSC transplantation if germ cell depletion was due to the inability of SSCs to maintain undifferentiated state or loss of SSCs (Naughton et al. 2006).

Downstream signaling pathways potentially activated by RET tyrosine phosphorylation include Janus kinase/signal transducer and activator of transcription, Src family kinase (SFK), mitogen-activated protein kinase (MAPK), protein kinase $\mathrm{C}$, and phosphatidylinositol 3-kinase (PI3K)/protein kinase B (Akt; reviewed in Ichihara et al. (2004) and Arighi et al. (2005)). Investigations of the downstream signaling in SSCs and undifferentiated spermatogonia following GDNF treatment have demonstrated that at least two of the signaling pathways are active in SSCs and undifferentiated spermatogonia. However, the biological outcome of the activation of different signaling pathways in SSCs by GDNF indicates that in addition to SSC self-renewal, GDNF is also important for basic SSC survival and function (Oatley et al. 2007).

Microarray gene expression profiling was used to identify genes regulated by GDNF that are potentially involved in SSC proliferation and survival (Oatley et al. 2007). These researchers established SSC cultures with the use of a serumfree medium containing GDNF, GFR $\alpha 1$, and bFGF and then eliminated GDNF signaling in these cells by removing GDNF and soluble GFR $\alpha 1$ from the medium for $18 \mathrm{~h}$. As expected, the expression of over 270 genes was significantly changed by the loss of GDNF-induced signaling. To identify genes induced by GDNF, gene expression profiles were obtained for SSC cultures 2, 4, and $8 \mathrm{~h}$ after GDNF and GFR $\alpha 1$ were added back to the culture medium. A group of genes with patterns of expression distinctly regulated by GDNF stimulation were identified (Oatley et al. 2007). Functional characterization of one of these genes, Bclob, with the use of RNA interference and SSC transplantation demonstrated that suppressing $B c l 6 b$ expression results in a 
loss of SSCs in culture (Oatley et al. 2007). In addition, targeted deletion of $B c l 6 b$ in mice results in smaller testes and seminiferous tubules with impaired germ cell differentiation. These results support the hypothesis that Bcl6b is important for SSC function; however, since the knockout mice are fertile, Bcl6b is likely not necessary for SSC self-renewal and proliferation but important for maximum sperm production.

As discussed above, multiple signaling cascades can be induced by GDNF via its interaction with RET. Investigation of downstream signaling in SSCs following GDNF treatment has yielded interestingly contradictory results with regard to cell self-renewal and proliferation versus survival. These differences may be due to purity of the undifferentiated spermatogonia in culture or the strain of mouse used by respective research groups. SSCs obtained from DBA/2 mice can survive in culture for long periods with or without fibroblast feeder layers (Kanatsu-Shinohara et al. 2005). Removal of GDNF from these cultures significantly reduced SSC proliferation; however, inhibition of MEK signaling in the presence of GDNF with the specific inhibitor PD098059 did not alter SSC proliferation (Lee et al. 2007). Regulation of SSC proliferation in culture through the PI3K pathway was investigated with the PI3K inhibitor LY294002. Interestingly, LY294002 did inhibit SSC growth but did not stimulate differentiation of SSCs (Lee et al. 2007). Subsequent analysis demonstrated that GDNF treatment resulted in the phosphorylation of AKT, and that treating SSC cultures with LY294002 resulted in fewer colonies in recipient testes following SSC transplantation compared to controls. These data suggest that the activation of the PI3K pathway is important for SSC survival in culture (Lee et al. 2007). Oatley et al. (2007) also demonstrated that AKT is phosphorylated through the PI3K signaling cascade in SSCs following GDNF treatment. In addition, Oatley et al. (2007) showed that inhibition of AKT with a specific inhibitor significantly reduced the number of SSCs present in cultures as determined by the SSC transplantation assay. Assaying the expression of GDNF-induced genes in SSCs following treatment with the AKT inhibitor demonstrated that inhibition of AKT suppressed GDNF stimulation of Bcl6b, Erm, and Lhx1 (Oatley et al. 2007). Interestingly, inhibition of AKT also suppressed the expression of two genes in SSCs, Plzf and Pou5f1, which are not regulated by GDNF. The authors demonstrated that Bcl6b, Erm, and Lhx1 are important for SSC renewal, because suppressing their expression with the use of RNA interference resulted in fewer SSCs as determined by SSC transplantation. The result that inhibition of AKT resulted in the suppression of GDNF-regulated and non-GDNF-regulated genes in SSCs guided these researchers to conclude that AKT is important for basic SSC survival but not necessarily for SSC self-renewal.

GDNF can activate multiple signaling pathways through its interaction with RET. A signaling pathway investigated in SSCs following GDNF treatment involves the SFKs. SSCs cultured in the presence of GDNF express the SFK members $c$-Src, Yes, Fyn, Lyn, and Hck and GDNF treatment of SSC cultures following overnight withdrawal of GDNF demonstrated that $c$-Src is phosphorylated after GDNF treatment (Oatley et al. 2007). Activation of SFKs is functionally significant in SSCs as demonstrated with treatment of SU6655, a selective chemical inhibitor of SFKs. Not only did SU6644 treatment block phosphorylation of AKT it also blocked GDNF induction of Bcl6b, Erm, and Lhx 1 and reduced the number of SSCs in culture (Oatley et al. 2007). In contrast to inhibition of AKT (see previous paragraph), inhibition of SFKs did not suppress expression of Plzf and Pou5f1 in SSC cultures. These data support the hypothesis that SFKs are important for SSC self-renewal in addition to mediating the Akt-supported general survival of SSCs (Oatley et al. 2007). Src phosphorylation also appears to be a pre requisite for $\mathrm{PI} 3 \mathrm{~K} / \mathrm{AKT}$ signaling and induction of $\mathrm{N}$-myc expression in GDNF treated, GRF $\alpha 1$-positive spermatogomia isolated from the testis of mice 4.5 to 5 days after birth (Braydich-Stolle et al. 2007) Thus, activation of an Src/PI3K-dependent pathway involving AKT phosphorylation is critical to support GDNF-induced ssc proliferation (Braydich-Stolle et al. 2007).

RET is phosphorylated at multiple tyrosine residues on the cytoplasmic tail of the protein, and these phosphorylation sites serve as binding sites for proteins that regulate downstream signaling cascades (Ichiharaet al. 2004). Mutation of RET tyrosine 1062 results in the loss of germ cells during the first 4 weeks of life such that there are no differentiating germ cells by day 28 after birth (Jijiwa et al. 2004). Interestingly, there was no increase in apoptosis in the seminiferous tubules of RET tyrosine 1062 mutant mice compared to controls suggesting that the SSCs in tyrosine 1062 mutant mice differentiate at an accelerated rate leading to depletion or exhaustion of the SSC population early in life (Jijiwa et al. 2004). Therefore, mutation of the RET tyrosine 1062 may not disrupt the formation of the SSC population in neonatal mice because spermatocytes are present in tyrosine 1062 mutant mice 14 days after birth. Likewise, due to the fact that RET is expressed in $A_{p r}$ and $A_{a l}$ spermatogonia as well as SSCs, the observed phenotype may be independent of SSCs and represent the inability of undifferentiated spermatogonia to initiate the differentiation process to eventually become meiotic germ cells. GDNF signaling appears to regulate the survival and maintain germ cell fate in SSCs (Oatley et al. 2007), and tyrosine 1062 may be a key regulation point for both functions. Thus, further investigation of SSCs from the RET tyrosine 1062 mutant such as SSC transplantation experiments to determine if SSCs are present in post pubertal animals would be instrumental in determining if the primary GDNF signal transduction in SSCs occurs through tyrosine 1062.

\section{SSC gene expression profiling}

Gene expression profiling has also been investigated in GFR $\alpha 1$-selected spermatogonia (Hofmann et al. 2005). A combination of cell separation with a BSA gradient and 
selection for GFR $\alpha 1$-positive cells with magnetic beads was used to isolate spermatogonia from mice 6 days after birth. These cells were incubated with GDNF for $10 \mathrm{~h}$ in medium containing $10 \%$ NuSerum, and the RNA from these cells was used to identify GDNF-regulated genes. As determined with the use of gene microarrays, over 1100 genes were differentially regulated by GDNF compared to controls (Hofmann et al. 2005).

These data are interesting in comparison with the gene microarray analysis of SSCs cultured with GDNF conducted by Oatley et al. (2006). Based on the comparison of published lists of regulated genes, the genes with the largest change in expression following GDNF treatment are not consistent between studies. This could be due to the different isolation and culture conditions in the two studies. Hofmann et al. (2005) treated freshly isolated GFR $\alpha 1$-positive spermatogonia with GDNF for $10 \mathrm{~h}$, while Oatley et al. (2006) treated SSCs that had been cultured for several weeks. In addition, Oatley et al. (2006) analyzed gene expression in cultured SSCs at shorter intervals (2, 4, and $8 \mathrm{~h}$ ) than Hofmann et al. (2005), suggesting that GDNF could induce the expression of a subset of early immediate genes and additional genes that are downstream of the initial group of genes. Oatley et al. (2006) used a serum-free culture that only included exogenous bFGF in addition to the GDNF and soluble GFR $\alpha 1$, while Hofmann et al. (2005) did not add exogenous bFGF or soluble GFR $\alpha 1$ but did supplement the medium with $10 \%$ $\mathrm{NuSerum}$. Although different culture conditions can support SSCs, the inclusion of serum has been shown to reduce SSC proliferation or survival in vitro (Kubota et al. 2004).

Hofmann et al. (2005) reported that $\sim 50 \%$ of the GFR $\alpha 1$ cells were positive for kit, while Oatley et al. (2006) reported that the cultured SSCs in their study were negative for kit protein based on immunofluorescent staining. Two reports demonstrated that kit-positive cells from adult cryptorchid mice did not have SSC colonization activity potential based on SSC transplantation experiments (Shinohara et al. 2000, Kubota et al. 2003). A similar study demonstrated that the kit-positive cells from the testes of mice at $7 \cdot 5$ days of age did not colonize the testes of recipient mice (Ohbo et al. 2003). Thus, the cell population in the Hoffman et al. (2005) gene profiling experiments may have been a mixed germ cell population including differentiated spermatogonia and undifferentiated spermatogonia. Also, the GFR $\alpha 1$-positive cells were isolated from the testes of mice 6 days after birth when the hierarchy of the germ cell population has not been completely established. Indeed, the first wave of spermatogenesis is less efficient than subsequent rounds with several interesting differences (de Rooij \& Russell 2000). Expression of some genes associated with spermatogonia differentiation in neonatal germ cells is different than germ cells from adults (Yoshida et al. 2006), and a wave of apoptosis occurs in germ cells during early testis development (Mori et al. 1997, Rodriguez et al. 1997, Russell et al. 2002). Therefore, it is possible, especially in different strains of mice, that during the first week of life, gene expression in SSCs and undifferentiated spermatogonia may not be as tightly regulated as in adult mice. These differences may partially explain the variation in gene expression responses to GDNF reported in these two studies.

\section{Crosstalk and GDNF-independent signaling in SSCs}

The activation of several signaling cascades by GDNF binding to GFR $\alpha 1$ and RET raises the possibility that crosstalk between signaling pathways may regulate SSCs. For example, in the developing kidney, crosstalk between vascular endothelial growth factor (VEGF) and GDNF occurs in ureteric bud-derived cells (Tufro et al. 2007). VEGF induces phosphorylation at RET tyrosine 1062, and both binding of VEGF to its receptor KDR and binding of GDNF to RET have an additive effect on phosphorylation at tyrosine 1062. In rodents, Leydig and Sertoli cells produce VEGF, and Leydig expression is stimulated by human chorionic gonadotropin (hCG) treatment (Nalbandian et al. 2003, Rudolfsson et al. 2004). In mice and human testes, Leydig cells express the VEGF receptors KDR and FLT1 (Ergun et al. 1997, Korpelainen et al. 1998). We have shown that VEGF treatment of bovine testis tissue increases germ cell differentiation resulting in more sperm produced in testis tissue grafts (Schmidt et al. 2006). Based on these results and expression of KDR by spermatogonia, we hypothesized that VEGF stimulates spermatogonia proliferation. Treating testis tissue from 4- to 8-week calves that contain spermatogonia as the only germ cell with VEGF resulted in an increase in spermatogonia compared to controls treated with vehicle (Caires et al. 2009). VEGF induces the expression of genes that promote germ cell survival in the testis tissue (Caires et al. 2009), suggesting that one nonvascular role of VEGF signaling in the testis is promoting spermatogonial survival during testis development. Thus, the interaction between GDNF and VEGF may promote general cell survival in SSCs as well as undifferentiated spermatogonia.

GDNF signaling independent of RET in cells that express GFR $\alpha 1$ has been demonstrated in vivo and in vitro (Paratcha \& Ledda 2008). Alternatively to RET binding, the GDNF/ GFRa1 complex can bind with neural cell adhesion molecule (NCAM) to stimulate signaling in cultured Schwann cells and stimulate axonal in hippocampal and cortical neurons in addition to other biological functions (Paratcha et al. 2003, Paratcha \& Ledda 2008). Cultured SSCs from mice and rats express NCAM suggesting that GDNF may mediate changes in SSCs through interaction with NCAM. GDNF binding to NCAM is stabilized by GFR $\alpha 1$, and this interaction causes a reduction in NCAM-regulated homophilic cell adhesion (Sjostrand et al. 2007). The interaction between NCAM and GDNF in the testis may regulate the migration of SSCs away from the SCC niche when cellular differentiation program initiates to switch SSC activity away from GDNF-regulated self-renewal. Alternatively, parallel signaling pathways could also be activated to regulate cell fate. 


\section{Regulation of GDNF expression}

Cellular and physiological actions of RET activation by GDNF binding have been demonstrated in the kidney, neural tissue, and the testis (Sariola \& Saarma 2003). While is it known that GDNF is very important in SSC biological activity in the testis, little is known about what regulates its expression in this tissue. GDNF mRNA and protein have been localized in Sertoli cells (Meng et al. 2000), spermatogonia, and spermatids in the mouse (Yu et al. 2003). Similar results have been reported for rats and humans (Fouchecourt et al. 2006). As shown in Fig. 1, the expression pattern of GDNF is not restricted to germ cells, while RET is expressed in a subset of spermatogonia. The expression of the phosphorylated form of RET varies between seminiferous tubules, suggesting that it has a stage-specific regulation (Fig. 1). This suggests that the regulation of SSC proliferation and self-renewal may be more dependent on the expression and phosphorylation of the receptors rather than the availability of GDNF in the seminiferous tubule.

FSH increases the expression of GDNF $3 \mathrm{~h}$ after treatment in cultures of primary Sertoli cells from 14-day-old mice (Tadokoro et al. 2002). In fact, these researchers suggest that FSH stimulation via homeostatic control is a major regulator of GDNF concentration in the testis. However, this conclusion is based on data in which a GNRH antagonist (Nal-Glu) is used to suppress FSH. This approach would also suppress testosterone production so the role of testosterone in this homeostatic regulation is not known (Tadokoro et al. 2002).

In another study, the mouse Sertoli cell line TM4 was used to investigate regulation of GDNF expression. FGF2 at $25 \mathrm{ng} / \mathrm{ml}$ stimulated GDNF expression fivefold in TM4 cells $48 \mathrm{~h}$ after treatment, while FSH stimulated GDNF expression twofold in TM4 cells 3-24 h after treatment (Simon et al. 2007). Stimulation of GDNF expression by FGF2 in TM4 cells was suppressed by pretreatment of the TM4 cells with the PI3K inhibitor wortmannin and the MAPK signaling inhibitor PD98059. However, neither inhibitor alone or when added together completely abolished the FGF2 stimulated increase of GDNF expression. This indicates that other cellular mechanisms in addition to the MAPK and PI3K pathways are involved in FGF2 induction of GDNF expression. FSH increased GDNF expression 2-1-fold $6 \mathrm{~h}$ after treatment in primary Sertoli cells from 10-day-old mice. Similarly, FGF2 treated resulted in a 1.92 -fold increase in Gdnf mRNA levels $48 \mathrm{~h}$ after treatment (Simon et al. 2007). However, experiments with wortmannin and PD98059 were not performed with FGF2- or FSH-treated primary mouse Sertoli cells.

The role of FGF2 regulation of GDNF expression in the testis may be complex based on the fact that FGF2 has been shown to play a role in SSC survival in vitro (Kubota et al. 2004, Hofmann et al. 2005) but SSCs do not express GDNF (Oatley et al. 2006). Similarly, the role of FGF2 in the testis is complicated by the fact that the FGF2 knockout mouse is fertile (Ortega et al. 1998). Thus, information regarding the cellular and molecular mechanisms regulating GDNF expression in the testis is lacking and represents a gap in the field. Similarly, information about GDNF expression by Sertoli cells is based on experimentation using prepubertal rodents as the source of Sertoli cells. Sertoli cell response to FSH declines in sexually mature animals; however, it is still biologically important, especially for spermatogonial differentiation. Therefore, details about how FSH may contribute to maintenance of SSCs by regulating the expression of GDNF or other factors in sexually mature animals have not been determined.

\section{Retinol and retinoic acid}

Vitamin A is essential for male fertility and normal spermatogenesis in rats and mice (Morales \& Griswold 1987, van Pelt \& de Rooij 1990). RA, an active metabolite of vitamin $A$, is critical for the differentiation of spermatogonia and entry of germ cells into meiosis (Bowles \& Koopman 2007). Vitamin A deficiency in rats results in a block of germ cell differentiation such that only spermatogonia and scant preleptotene spermatocytes are present while mice have only undifferentiated spermatogonia. RA receptors are expressed in both germ and somatic cells in the testis (Dufour \& Kim 1999), so RA can regulate germ cells directly or regulate the somatic cells that contribute to the SSC niche. According to microarray data, cultured SSCs express $\operatorname{RXR} \alpha, \operatorname{RXR} \beta$, and $\operatorname{RAR} \alpha$, and the expression of these genes is not regulated by GDNF (Oatley et al. 2006). Therefore, there is potential of direct RA regulation of SSCs. Dann et al. (2008) demonstrated that repressing Pouff1 with shRNA resulted in a reduction of the ability of cultured spermatogonia to colonize the testes of recipient mice after transplantation. In addition, RA represses Pou5f1 expression in cultured spermatogonia supporting the hypothesis that RA stimulates differentiation of SSCs (Dann et al. 2008). These data suggest a second mechanism that may regulate SSC differentiation in addition to the loss of GDNF signaling especially considering the fact that the expression of Pou $5 f 1$ did not change in SSCs when GDNF/GFRa1 were removed and added back to SSC cultures (Oatley et al. 2006). As with other publications described previously in this review, there are several differences between the culture conditions, analysis of transplantation data and the strain of mice used for spermatogonial enrichment. For example, the use of DBA/ 2 (Dann et al. 2008) versus C57Bl/6 (Oatley et al. 2006) mice as the source of SSCs complicates the comparison of the data and may provide explanation for contradictory data.

The block in spermatogonial differentiation in vitamin A-deficient mice provides a unique animal model to investigate RA regulation of SSCs in vivo. We hypothesized that the testis of vitamin A-deficient mice would be naturally enriched for SSCs based on the loss of differentiating germ 
cells in this model. Similarly, the testes of neonatal mice and cryptorchid testes in adult mice are enriched for SSCs because differentiating germ cells are not present (Shinohara et al. 2000, McLean et al. 2003). Unexpectedly, as demonstrated by SSC transplantation, the number of biologically active SSCs in the testes of vitamin A-deficient mice was significantly less than that would be expected based on the regression of the testis (McLean et al. 2002). Based on the fact that some receptors for RA are expressed in SSCs and somatic cells that comprise the niche, it is not known if the lack of RA signaling in vitamin A-deficient mice directly to the SSCs or to the somatic cells is the cause of the loss of SSCs in this model. The vitamin A-deficient mice must be the offspring of breeding pairs maintained on vitamin A-deficient diet prior to fertilization, during gestation and through lactation. Approximately 12 weeks after weaning and maintenance on vitamin A-deficient diet, testicular regression is complete in the deficient animals. Close inspection of this protocol reveals that that vitamin A-deficient mice are not exposed to RA during the formation of the SSC population in neonatal mice or in the maintenance of the SSC population in adults. Thus, RA may be important for the formation of the SSC population that occurs during the first 3-4 days of life in mice (McLean et al. 2003) or in the maintenance of the SSC population in adults or both.

\section{Vasculature-associated niche}

The lack of a specific marker for SSCs and the small number of SSCs present in the testis have prevented identification of the physical location of the SSC niche in the seminiferous tubule. In other adult stem cell systems, the niche can be comprised of multiple somatic cells and extracellular matrix (ECM) components. The synthesis and turnover rate of growth factors and other biologically active molecules produced in the niche microenvironment could also be regulated by changes in local tissue activity and, or in response to extrinsic cues. The potential regulation of the SSC niche with systemic endocrine factors suggests that the physical location of SSCs and the niche may need to be in close proximity to the vascular system. This hypothesis was tested with the use of three-dimensional culture system and image capturing system (Yoshida et al. 2007). These researchers localized undifferentiated spermatogonia in transgenic mice expressing GFP under the control of the $\mathrm{Ngn} 3$ regulatory sequence. Undifferentiated spermatogonia are preferentially localized to the vascular network and interstitial space surrounding the seminiferous tubules (Yoshida et al. 2007). Over time, they observed that differentiating spermatogonia move from the area of the seminiferous tubule associated with the vascular network into a random pattern throughout the tubule. We have seen a similar cell localization pattern for cells positive for the undifferentiated spermatogonial expressed protein PLZF in adult mice (Fig. 1). Approximately $20 \%$ of the tubules in a total testis cross-section (20 out of 125 total tubules) have germ cells positive for PLZF, and on average, about one germ cell per tubule in a cross-section is PLZF positive. The majority of these germ cells are close to the interstitial space, although two-dimensional morphological images must be evaluated with caution due to the inability to view structures above and below the tissue section.

The close association of the niche to the vasculature and interstitial cells, including Leydig cells, hypothesized by Yoshida et al. (2007) implies that transfer of factors transported in the blood or from the interstitial cells is critical for SSC maintenance, differentiation, or both. This organization has been proposed for other adult stem cell systems and would provide a means for systemic endocrine regulation of the SSC niche. The niche would be more plastic and possibly change location if dependent on vascular and interstitial regulation.

\section{Testosterone regulation of spermatogonia}

Androgen receptor (AR) is expressed in testicular somatic cells, Sertoli, Leydig, and peritubular myoid, which may all contribute to the SSC niche (Walker \& Cheng 2005, Tsai et al. 2006). Multiple genes regulated by testosterone in vivo have been identified in the testis (Sadate-Ngatchou et al. 2004), but the molecular mechanisms by which testosterone regulates somatic and germ cell function in the testis are unclear. Reports of AR expression in differentiating germ cells have been controversial because of conflicting data on which germ cells express AR. The data indicates that AR expression is present in some differentiating germ cells in certain species. Elongated spermatids have been shown to express AR and the AR-specific co-regulator, SNURF/ RNF4 (Vornberger et al. 1994, Yan et al. 2002). In addition, we have unpublished data that gonocytes express AR during neonatal life in pigs and bulls.

The expression of AR in differentiating germ cells is not required for spermatogenesis because transplantation of germ cells from the naturally occurring AR mutants called testicular feminized ( $\mathrm{fm}$ ) mice into the testes of wild-type mice resulted in complete germ cell differentiation (Johnston et al. 2001). These results suggest that germ cells do not need to express AR in order to differentiate into sperm. However, numerous reports have demonstrated that AR expression in Sertoli cells is essential for germ cell differentiation into sperm (De Gendt et al. 2004, Holdcraft \& Braun 2004).

Testosterone is essential for testis development and sustained spermatogenesis. However, recovery of spermatogonial proliferation is blocked by testosterone following cytotoxic damage to the testis in rats from multiple toxicants including radiation (Meistrich \& Shetty 2003, Shetty et al. 2006a). In addition, FSH also blocks spermatogonial proliferation independently of testosterone following irradiation. The negative action of FSH and testosterone on spermatogonial proliferation in this model is independent of SSCs and is due to the somatic environment. Radiation does not alter the functional ability of rat SSCs to colonize the 
seminiferous tubules of recipient immunodeficient nude mice. The block on spermatogonial differentiation in irradiated rats is actually due to damage to the somatic cells in the testis. This was demonstrated with the use of SSC transplantation by the transplantation of germ cells from irradiated rats into the testes of irradiated or untreated recipient rats (Zhang et al. 2007). Suppression of testosterone was necessary for colonized rat SSCs to differentiate in the testes of irradiated rat recipients but testosterone suppression was not required if the rat SSCs were injected into the seminiferous tubules of control recipient rats. Interestingly, transplantation of rat SSCs into the seminiferous tubules of bulsulfan-treated or irradiated mouse testes demonstrated that the colonization of the rat SSCs and subsequent spermatogonial differentiation were not inhibited by the high intratesticular testosterone concentrations in irradiated mice. Thus, the block of spermatogonial differentiation due to high concentrations of FSH and testosterone following irradiation appears to be specific to rats (Zhang et al. 2007).

The age-related decline in testosterone is due to testicular aging, and at least $30 \%$ of men $>60-70$ years of age have low testosterone concentrations (Hijazi \& Cunningham 2005). Testicular aging may be due to decreased Leydig cell function or changes in the pulsatility of LH leading to a decreased production of testosterone. A similar decline in serum testosterone is observed at 15 months of age in mice, leading to a severe depletion of germ cells and the presence of vacuoles in the seminiferous epithelium (Lacombe et al. 2006). Indeed, up to $70 \%$ of the seminiferous tubules in 15-month-old mice show degeneration. Ryu et al. (2006) showed that SSCs from 12 to 24-month-old mice maintain their activity when transplanted into the testes of young mice suggesting that SSCs are functional past the lifespan of the male. These authors concluded that infertility in old males results from deterioration of the SSC niche and a failure of the niche to support the appropriate balance between stem cell self-renewal and differentiation (Ryu et al. 2006). These results, taken with the report that the lack of AR expression in peritubular myoid cells leads to oligospermia (Zhang et al. 2006), indicate that testosterone is needed to support the SSC niche and sperm production throughout the lifespan of the male. Likewise, the decrease in serum testosterone levels during aging in males leads to a decrease in the number of SSCs resulting in decreased sperm production.

\section{Conclusions and future directions}

The central two questions addressed in this review - what stimulates a SSC to self-renew and what stimulates a SSC to commit to differentiation provide the framework around which regulation of the SSC population is formed. Much is expected of SSCs including maintaining a stable population that can produce progeny cells for the majority of the life of the male. Beyond this function, the homeostasis of the cell population, cellular mechanisms must maintain precise

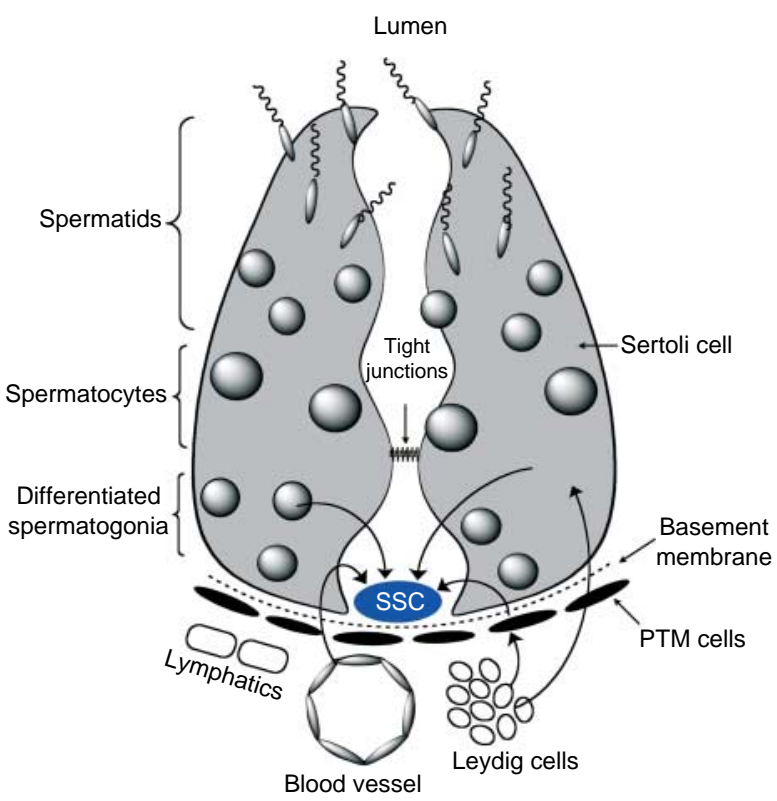

Figure 2 Diagram is a model of spermatogonial stem cell and somatic cells contributing to the SSC niche. This model demonstrates the sources of potential autocrine, paracrine, and environmental cues that may influence spermatogonial stem cell fate in the mammalian testis.

replication of genetic material in SSCs because of the potential downstream contribution to the genome of offspring. Since the SSC is the only adult stem cell population that contributes genetic information to subsequent generations, the requirement of 'stemness' in SSCs may be more complex than other adult stem cells. Clearly defining the stemness of any adult stem cell population will improve our ability to discern the transdifferentiation potential of a cell and if adult stem cells have advantages over differentiated cells in this regard. Although external cues are known to regulate SSCs (Fig. 2), other adult stem cells are directed by intrinsic signals. Potentially intrinsic signals in SSCs may provide the stimulus of a SSC to differentiate with the loss of external signals to maintain stemness.

This review focused primarily on information gained with the use of rodent SSC models. However, translation of these findings to humans or agricultural species requires more comparative research on regulation of SSCs. In contrast to humans, the development of the testis and SSC population in rodents is rapid. Testis development in some large species (e.g. cattle, horses, pigs) falls between the rapid testis development in rodents and the protracted testis development in humans. Investigation of the process of the formation and maintenance of the SSC population in different species will establish if the same mechanisms regulating SSCs in rodents are used in all species and if the process just takes longer or if unique signals are required to maintain future SSCs in a quiescent state. The small number and lack of specific marker for SSCs in the testis 
create challenges to investigate the regulation of these cells; however, expansion of our knowledge base about the mechanisms for self-renewal provide the basis for understanding the mechanisms regulating differentiation and the regulation of factors produced by the somatic cells of the niche that influence these processes.

\section{Declaration of interest}

The authors declare that there is no conflict of interest that could be perceived as prejudicing the impartiality of the research reported.

\section{Funding}

Supported by grants from the Eunice Kennedy Shriver National Institute of Child Health and Human Development.

\section{Acknowledgements}

The author's extend thanks to Drs Michael Griswold, Qing Zhou, J Andrew Schmidt, and Jon Oatley for helpful discussion and Jeanene de Avila for technical assistance.

\section{References}

Airaksinen MS \& Saarma M 2002 The GDNF family: signalling, biological functions and therapeutic value. Nature Reviews. Neuroscience 3 383-394.

Arighi E, Borrello MG \& Sariola H 2005 RET tyrosine kinase signaling in development and cancer. Cytokine and Growth Factor Reviews 16 441-467.

Avarbock MR, Brinster CJ \& Brinster RL 1996 Reconstitution of spermatogenesis from frozen spermatogonial stem cells. Nature Medicine 2 693-696.

Boettger-Tong HL, Johnston DS, Russell LD, Griswold MD \& Bishop CE 2000 Juvenile spermatogonial depletion (jsd) mutant seminiferous tubules are capable of supporting transplanted spermatogenesis. Biology of Reproduction 63 1185-1191.

Bowles J \& Koopman P 2007 Retinoic acid, meiosis and germ cell fate in mammals. Development 134 3401-3411.

Braydich-Stolle L, Kostereva N, Dym M \& Hofmann MC 2007 Role of Src family kinases and N-Myc in spermatogonial stem cell proliferation. Developmental Biology 304 34-45.

Brinster RL \& Zimmermann JW 1994 Spermatogenesis following male germ-cell transplantation. PNAS 91 11298-11302.

Buaas FW, Kirsh AL, Sharma M, McLean DJ, Morris JL, Griswold MD, de Rooij DG \& Braun RE 2004 Plzf is required in adult male germ cells for stem cell self-renewal. Nature Genetics 36 647-652.

Caires KC, de Avila J \& McLean DJ 2009 Vascular endothelial growth factor regulates germ cell survival during establishment of spermatogenesis in the bovine testis. Reproduction 138 667-677.

Creemers LB, Meng X, den Ouden K, van Pelt AM, Izadyar F, Santoro M, Sariola H \& de Rooij DG 2002 Transplantation of germ cells from glial cell line-derived neurotrophic factor-overexpressing mice to host testes depleted of endogenous spermatogenesis by fractionated irradiation. Biology of Reproduction 66 1579-1584.

Dann CT, Alvarado AL, Molyneux LA, Denard BS, Garbers DL \& Porteus MH 2008 Spermatogonial stem cell self renewal requires OCT4, a factor down-regulated during retinoic acid induced differentiation. Stem Cells 26 2928-2937.
De Gendt K, Swinnen JV, Saunders PT, Schoonjans L, Dewerchin M, Devos A, Tan K, Atanassova N, Claessens F, Lecureuil C et al. 2004 A Sertoli cell-selective knockout of the androgen receptor causes spermatogenic arrest in meiosis. PNAS 101 1327-1332.

Dufour JM \& Kim KH 1999 Cellular and subcellular localization of six retinoid receptors in rat testis during postnatal development: identification of potential heterodimeric receptors. Biology of Reproduction 61 1300-1308.

Ergun S, Kilic N, Fiedler W \& Mukhopadhyay AK 1997 Vascular endothelial growth factor and its receptors in normal human testicular tissue. Molecular and Cellular Endocrinology 131 9-20.

Fouchecourt S, Godet M, Sabido O \& Durand P 2006 Glial cell-line-derived neurotropic factor and its receptors are expressed by germinal and somatic cells of the rat testis. Journal of Endocrinology 190 59-71.

Fuchs E, Tumbar T \& Guasch G 2004 Socializing with the neighbors: stem cells and their niche. Cell 116 769-778.

Fuller MT \& Spradling AC 2007 Male and female Drosophila germline stem cells: two versions of immortality. Science 316 402-404.

Guan K, Nayernia K, Maier LS, Wagner S, Dressel R, Lee JH, Nolte J, Wolf F, Li M, Engel W et al. 2006 Pluripotency of spermatogonial stem cells from adult mouse testis. Nature $\mathbf{4 4 0}$ 1199-1203.

Hijazi RA \& Cunningham GR 2005 Andropause: is androgen replacement therapy indicated for the aging male? Annual Review of Medicine 56 117-137.

Hofmann MC, Braydich-Stolle L \& Dym M 2005 Isolation of male germ-line stem cells; influence of GDNF. Developmental Biology 279 114-124.

Holdcraft RW \& Braun RE 2004 Androgen receptor function is required in Sertoli cells for the terminal differentiation of haploid spermatids. Development 131 459-467.

Ichihara M, Murakumo Y \& Takahashi M 2004 RET and neuroendocrine tumors. Cancer Letters 204 197-211.

Jain S, Naughton CK, Yang M, Strickland A, Vij K, Encinas M, Golden J, Gupta A, Heuckeroth R, Johnson EM Jr et al. 2004 Mice expressing a dominant-negative Ret mutation phenocopy human Hirschsprung disease and delineate a direct role of Ret in spermatogenesis. Development 131 5503-5513.

Jijiwa M, Fukuda T, Kawai K, Nakamura A, Kurokawa K, Murakumo Y, Ichihara M \& Takahashi M 2004 A targeting mutation of tyrosine 1062 in Ret causes a marked decrease of enteric neurons and renal hypoplasia. Molecular and Cellular Biology 24 8026-8036.

Johnston DS, Russell LD, Friel PJ \& Griswold MD 2001 Murine germ cells do not require functional androgen receptors to complete spermatogenesis following spermatogonial stem cell transplantation. Endocrinology 142 2405-2408.

Kanatsu-Shinohara M, Inoue K, Lee J, Yoshimoto M, Ogonuki N, Miki H, Baba S, Kato T, Kazuki Y, Toyokuni S et al. 2004 Generation of pluripotent stem cells from neonatal mouse testis. Cell 119 1001-1012.

Kanatsu-Shinohara M, Miki H, Inoue K, Ogonuki N, Toyokuni S, Ogura A \& Shinohara T 2005 Long-term culture of mouse male germline stem cells under serum-or feeder-free conditions. Biology of Reproduction 72 985-991.

Kanatsu-Shinohara M, Muneto T, Lee J, Takenaka M, Chuma S, Nakatsuji N, Horiuchi T \& Shinohara T 2008 Long-term culture of male germline stem cells from hamster testes. Biology of Reproduction 78 611-617.

Korpelainen EI, Karkkainen MJ, Tenhunen A, Lakso M, Rauvala H, Vierula M, Parvinen M \& Alitalo K 1998 Overexpression of VEGF in testis and epididymis causes infertility in transgenic mice: evidence for nonendothelial targets for VEGF. Journal of Cell Biology 143 1705-1712.

Kubota H \& Brinster RL 2006 Technology insight: in vitro culture of spermatogonial stem cells and their potential therapeutic uses. Nature Clinical Practice. Endocrinology \& Metabolism 2 99-108.

Kubota H, Avarbock MR \& Brinster RL 2003 Spermatogonial stem cells share some, but not all, phenotypic and functional characteristics with other stem cells. PNAS 100 6487-6492.

Kubota H, Avarbock MR \& Brinster RL 2004 Growth factors essential for self-renewal and expansion of mouse spermatogonial stem cells. PNAS 101 16489-16494.

Lacombe A, Lelievre V, Roselli CE, Salameh W, Lue YH, Lawson G, Muller JM, Waschek JA \& Vilain E 2006 Delayed testicular aging in pituitary adenylate cyclase-activating peptide (PACAP) null mice. PNAS 103 3793-3798. 
Lee J, Kanatsu-Shinohara M, Inoue K, Ogonuki N, Miki H, Toyokuni S, Kimura T, Nakano T, Ogura A \& Shinohara T 2007 Akt mediates self-renewal division of mouse spermatogonial stem cells. Development $1341853-1859$.

McLean DJ 2008 Spermatogonial stem cell transplantation, testicular function, and restoration of male fertility in mice. In Germline Stem cells, vol 450, pp 149-162. Eds SX Hou \& SR Singh. Totowa, NJ: Humana Press.

McLean DJ, Russell LD \& Griswold MD 2002 Biological activity and enrichment of spermatogonial stem cells in vitamin A-deficient and hyperthermia-exposed testes from mice based on colonization following germ cell transplantation. Biology of Reproduction 66 1374-1379.

McLean DJ, Friel PJ, Johnston DS \& Griswold MD 2003 Characterization of spermatogonial stem cell maturation and differentiation in neonatal mice. Biology of Reproduction 69 2085-2091.

Meistrich ML \& van Beek MEAB 1993 Spermatogonial stem cells: assessing their survival and ability to produce differentiated cells. In Methods in Toxicology, vol 3A, pp 106-123. Eds J Heindel \& RE Chapin. New York, NY: Academic Press.

Meistrich ML \& Shetty G 2003 Inhibition of spermatogonial differentiation by testosterone. Journal of Andrology 24 135-148.

Meng X, Lindahl M, Hyvonen ME, Parvinen M, de Rooij DG, Hess MW, Raatikainen-Ahokas A, Sainio K, Rauvala H, Lakso M et al. 2000 Regulation of cell fate decision of undifferentiated spermatogonia by GDNF. Science 287 1489-1493.

Meng X, de Rooij DG, Westerdahl K, Saarma M \& Sariola H 2001 Promotion of seminomatous tumors by targeted overexpression of glial cell line-derived neurotrophic factor in mouse testis. Cancer Research $\mathbf{6 1}$ 3267-3271.

Morales C \& Griswold MD 1987 Retinol-induced stage synchronization in seminiferous tubules of the rat. Endocrinology 121 432-434.

Mori C, Nakamura N, Dix DJ, Fujioka M, Nakagawa S, Shiota K \& Eddy EM 1997 Morphological analysis of germ cell apoptosis during postnatal testis development in normal and Hsp 70-2 knockout mice. Developmental Dynamics 208 125-136.

Nagano MC 2003 Homing efficiency and proliferation kinetics of male germ line stem cells following transplantation in mice. Biology of Reproduction $\mathbf{6 9}$ 701-707.

Nakagawa T, Nabeshima Y \& Yoshida S 2007 Functional identification of the actual and potential stem cell compartments in mouse spermatogenesis. Developmental Cell 12 195-206.

Nalbandian A, Dettin L, Dym M \& Ravindranath N 2003 Expression of vascular endothelial growth factor receptors during male germ cell differentiation in the mouse. Biology of Reproduction $69985-994$.

Naughton CK, Jain S, Strickland AM, Gupta A \& Milbrandt J 2006 Glial cell-line derived neurotrophic factor-mediated RET signaling regulates spermatogonial stem cell fate. Biology of Reproduction 74 314-321.

Oakberg EF 1956 Duration of spermatogenesis in the mouse and timing of stages of the cycle of the seminiferous epithelium. American Journal of Anatomy 99 507-516.

Oatley JM \& Brinster RL 2008 Regulation of spermatogonial stem cell self-renewal in mammals. Annual Review of Cell and Developmental Biology 24 263-286.

Oatley JM, Reeves JJ \& McLean DJ 2004 Biological activity of cryopreserved bovine spermatogonial stem cells during in vitro culture. Biology of Reproduction 71 942-947.

Oatley JM, Avarbock MR, Telaranta AI, Fearon DT \& Brinster RL 2006 Identifying genes important for spermatogonial stem cell self-renewal and survival. PNAS 103 9524-9529.

Oatley JM, Avarbock MR \& Brinster RL 2007 Glial cell line-derived neurotrophic factor regulation of genes essential for self-renewal of mouse spermatogonial stem cells is dependent on Src family kinase signaling. Journal of Biological Chemistry 282 25842-25851.

Ohbo K, Yoshida S, Ohmura M, Ohneda O, Ogawa T, Tsuchiya H, Kuwana T, Kehler J, Abe K, Scholer HR et al. 2003 Identification and characterization of stem cells in prepubertal spermatogenesis in mice small star, filled. Developmental Biology 258 209-225.
Ortega S, Ittmann M, Tsang SH, Ehrlich M \& Basilico C 1998 Neuronal defects and delayed wound healing in mice lacking fibroblast growth factor 2. PNAS 95 5672-5677.

Orwig KE \& Schlatt S 2005 Cryopreservation and transplantation of spermatogonia and testicular tissue for preservation of male fertility. Journal of the National Cancer Institute. Monographs 2005 51-56.

Paratcha G \& Ledda F 2008 GDNF and GFRalpha: a versatile molecular complex for developing neurons. Trends in Neurosciences 31 384-391.

Paratcha G, Ledda F \& Ibanez CF 2003 The neural cell adhesion molecule NCAM is an alternative signaling receptor for GDNF family ligands. Cell $113867-879$.

van Pelt AM \& de Rooij DG 1990 Synchronization of the seminiferous epithelium after vitamin A replacement in vitamin A-deficient mice. Biology of Reproduction 43 363-367.

Pesce M, Wang X, Wolgemuth DJ \& Scholer H 1998 Differential expression of the Oct-4 transcription factor during mouse germ cell differentiation. Mechanisms of Development 71 89-98.

Rodriguez I, Ody C, Araki K, Garcia I \& Vassalli P 1997 An early and massive wave of germinal cell apoptosis is required for the development of functional spermatogenesis. EMBO Journal 16 2262-2270.

de Rooij DG \& Grootegoed JA 1998 Spermatogonial stem cells. Current Opinion in Cell Biology 10 694-701.

de Rooij DG \& Russell LD 2000 All you wanted to know about spermatogonia but were afraid to ask. Journal of Andrology 21 776-798.

Rudolfsson SH, Wikstrom P, Jonsson A, Collin O \& Bergh A 2004 Hormonal regulation and functional role of vascular endothelial growth factor a in the rat testis. Biology of Reproduction 70 340-347.

Russell LD, Chiarini-Garcia H, Korsmeyer SJ \& Knudson CM 2002 Bax-dependent spermatogonia apoptosis is required for testicular development and spermatogenesis. Biology of Reproduction 66 950-958.

Ryu BY, Kubota H, Avarbock MR \& Brinster RL 2005 Conservation of spermatogonial stem cell self-renewal signaling between mouse and rat. PNAS 102 14302-14307.

Ryu BY, Orwig KE, Oatley JM, Avarbock MR \& Brinster RL 2006 Effects of aging and niche microenvironment on spermatogonial stem cell selfrenewal. Stem Cells 24 1505-1511.

Sada A, Suzuki A, Suzuki H \& Saga Y 2009 The RNA-binding protein NANOS2 is required to maintain murine spermatogonial stem cells. Science 325 1394-1398.

Sadate-Ngatchou PI, Pouchnik DJ \& Griswold MD 2004 Identification of testosterone-regulated genes in testes of hypogonadal mice using oligonucleotide microarray. Molecular Endocrinology 18 422-433.

Santoro M, Melillo RM, Carlomagno F, Vecchio G \& Fusco A 2004 Minireview: RET: normal and abnormal functions. Endocrinology 145 5448-5451.

Sariola H \& Saarma M 2003 Novel functions and signalling pathways for GDNF. Journal of Cell Science 116 3855-3862.

Schlesser HN, Simon L, Hofmann MC, Murphy KM, Murphy T, Hess RA \& Cooke PS 2008 Effects of ETV5 (ets variant gene 5) on testis and body growth, time course of spermatogonial stem cell loss, and fertility in mice. Biology of Reproduction 78 483-489.

Schmidt JA, de Avila JM \& McLean DJ 2006 Effect of vascular endothelial growth factor and testis tissue culture on spermatogenesis in bovine ectopic testis tissue xenografts. Biology of Reproduction 75 167-175.

Seandel M, James D, Shmelkov SV, Falciatori I, Kim J, Chavala S, Scherr DS, Zhang F, Torres R, Gale NW et al. 2007 Generation of functional multipotent adult stem cells from GPR $125+$ germline progenitors. Nature 449 346-350.

Sharpe R 1994 Regulation of spermatogenesis. In The Physiology of Reproduction, vol 2, pp 1363-1434. Eds E Knobil \& JD Neill. New York, NY: Raven.

Shetty G, Weng CC, Meachem SJ, Bolden-Tiller OU, Zhang Z, Pakarinen P, Huhtaniemi I \& Meistrich ML 2006a Both testosterone and folliclestimulating hormone independently inhibit spermatogonial differentiation in irradiated rats. Endocrinology 147 472-482. 
Shetty G, Weng CC, Porter KL, Zhang Z, Pakarinen P, Kumar TR \& Meistrich ML 2006b Spermatogonial differentiation in juvenile spermatogonial depletion (jsd) mice with androgen receptor or follicle-stimulating hormone mutations. Endocrinology 147 3563-3570.

Shinohara T, Orwig KE, Avarbock MR \& Brinster RL 2000 Spermatogonial stem cell enrichment by multiparameter selection of mouse testis cells. PNAS 97 8346-8351.

Shinohara T, Orwig KE, Avarbock MR \& Brinster RL 2001 Remodeling of the postnatal mouse testis is accompanied by dramatic changes in stem cell number and niche accessibility. PNAS 98 6186-6191.

Simon L, Ekman GC, Tyagi G, Hess RA, Murphy KM \& Cooke PS 2007 Common and distinct factors regulate expression of mRNA for ETV5 and GDNF. Sertoli cell proteins essential for spermatogonial stem cell maintenance. Experimental Cell Research 313 3090-3099.

Simon L, Ekman GC, Kostereva N, Zhang Z, Hess RA, Hofmann MC \& Cooke PS 2009 Direct transdifferentiation of stem/progenitor spermatogonia into reproductive and nonreproductive tissues of all germ layers. Stem Cells 27 1666-1675.

Sjostrand D, Carlsson J, Paratcha G, Persson B \& Ibanez CF 2007 Disruption of the GDNF binding site in NCAM dissociates ligand binding and homophilic cell adhesion. Journal of Biological Chemistry 282 12734-12740.

Spradling A, Drummond-Barbosa D \& Kai T 2001 Stem cells find their niche. Nature 414 98-104.

Tadokoro Y, Yomogida K, Ohta H, Tohda A \& Nishimune Y 2002 Homeostatic regulation of germinal stem cell proliferation by the GDNF/FSH pathway. Mechanisms of Development 113 29-39.

Tegelenbosch RA \& de Rooij DG 1993 A quantitative study of spermatogonial multiplication and stem cell renewal in the C3H/101 F1 hybrid mouse. Mutation Research 290 193-200.

Tsai MY, Yeh SD, Wang RS, Yeh S, Zhang C, Lin HY, Tzeng CR \& Chang C 2006 Differential effects of spermatogenesis and fertility in mice lacking androgen receptor in individual testis cells. PNAS 103 18975-18980.

Tufro A, Teichman J, Banu N \& Villegas G 2007 Crosstalk between VEGF-A/VEGFR2 and GDNF/RET signaling pathways. Biochemical and Biophysical Research Communications 358 410-416.

Vornberger W, Prins G, Musto NA \& Suarez-Quian CA 1994 Androgen receptor distribution in rat testis: new implications for androgen regulation of spermatogenesis. Endocrinology 134 2307-2316.

Walker WH \& Cheng J 2005 FSH and testosterone signaling in Sertoli cells. Reproduction 130 15-28.
Yan X \& Owens DM 2008 The skin: a home to multiple classes of epithelial progenitor cells. Stem Cell Reviews 4 113-118.

Yan W, Hirvonen-Santti SJ, Palvimo JJ, Toppari J \& Janne OA 2002 Expression of the nuclear RING finger protein SNURF/RNF4 during rat testis development suggests a role in spermatid maturation. Mechanisms of Development 118 247-253.

Yoshida S, Takakura A, Ohbo K, Abe K, Wakabayashi J, Yamamoto M, Suda T \& Nabeshima Y 2004 Neurogenin3 delineates the earliest stages of spermatogenesis in the mouse testis. Developmental Biology 269 447-458.

Yoshida S, Sukeno M, Nakagawa T, Ohbo K, Nagamatsu G, Suda T \& Nabeshima Y 2006 The first round of mouse spermatogenesis is a distinctive program that lacks the self-renewing spermatogonia stage. Development 133 1495-1505.

Yoshida S, Sukeno M \& Nabeshima Y 2007 A vasculature-associated niche for undifferentiated spermatogonia in the mouse testis. Science 317 1722-1726.

Yu Z, Guo R, Ge Y, Ma J, Guan J, Li S, Sun X, Xue S \& Han D 2003 Gene expression profiles in different stages of mouse spermatogenic cells during spermatogenesis. Biology of Reproduction 69 37-47.

Zhang C, Yeh S, Chen YT, Wu CC, Chuang KH, Lin HY, Wang RS, Chang YJ, Mendis-Handagama C, Hu L et al. 2006 Oligozoospermia with normal fertility in male mice lacking the androgen receptor in testis peritubular myoid cells. PNAS 103 17718-17723.

Zhang Z, Shao S \& Meistrich ML 2007 The radiation-induced block in spermatogonial differentiation is due to damage to the somatic environment, not the germ cells. Journal of Cellular Physiology 211 149-158.

Zhou Q, Nie R, Prins GS, Saunders PT, Katzenellenbogen BS \& Hess RA 2002 Localization of androgen and estrogen receptors in adult male mouse reproductive tract. Journal of Andrology 23 870-881.

Zon LI 2008 Intrinsic and extrinsic control of haematopoietic stem-cell self-renewal. Nature 453 306-313.

Received in final form 23 December 2009

Accepted 10 February 2010

Made available online as an Accepted Preprint 10 February 2010 